\title{
Bauch oder Zahl?
}

\section{Anna Sax}

lic. oec. publ., MHA, Mitglied der Redaktion

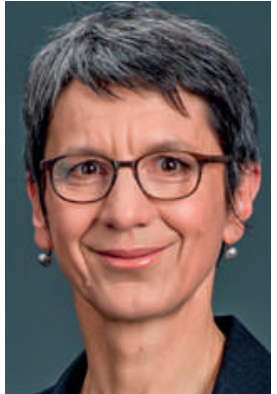

«Die Juristen haben wir gehört. Nun wollen wir noch den gesunden Menschenverstand sprechen lassen.» So oder ähnlich soll sich der Chef einer grösseren Beratungsfirma bei Besprechungen geäussert haben. Damit will er bestimmt nicht den Juristinnen den gesunden Menschenverstand absprechen. Vielmehr bringt er zum Ausdruck, dass es neben Fachwissen auch Erfahrung, Urteilsvermögen und Menschenkenntnis braucht, um bestimmte Probleme zu lösen. Die Erkenntnis gilt auch für andere Berufsgattungen, beispielsweise für Ärztinnen oder Ökonomen. Und doch werden Expertengutachten selten hinterfragt, gerade auch in der Gesundheits-

\section{Mit Zahlen wollte das BAG beweisen,} dass sich Prävention lohnt.

politik. Politiker argumentieren gern mit Zahlen, auch wenn sie am Schluss aus dem Bauch heraus entscheiden. Dass es medizinisches, juristisches, ethisches oder ökonomisches Fachwissen braucht, um zu guten gesundheitspolitischen Entscheidungen zu finden, ist unbestritten. Und doch wirft die weit verbreitete Zahlengläubigkeit auch Fragen auf, denn viele Zahlen sind von zweifelhafter Qualität. Zum Beispiel die Kosten ungesunden Verhaltens: Diese Berechnungen setzen sich meist aus direkten Krankheitskosten und Produktionsausfällen für die Wirtschaft zusammen. Vor allem für Letzeres gibt es unterschiedliche Berechnungsmethoden, die zu unterschiedlichen Resultaten führen. Fügt man die Studienresultate der letzten 10 Jahre zusammen, belasten Rauchen, Alkoholmissbrauch, Übergewicht, Stress und Freizeitunfälle die Schweizer Volkswirtschaft mit einem Betrag von gegen 30 Milliarden Franken. Rechnet man auch immaterielle Kosten hinzu, das wären dann Schmerz und Leid, steigen die Kosten je nach Berechnungsart um das Vier- bis Fünffache.

Einmal angenommen, man könnte zumindest in einer guten Annäherung abbilden, wie hoch die medizinischen und administrativen Kosten, Sachschäden und Produktionsausfälle sind, die durch ungesundes Verhalten verursacht werden, dann ergäbe das gute Argumente für die Forderung nach mehr Prävention. So bringe zum Beispiel jeder in die Tabakprävention investierte Franken einen Nettoertrag von 41 Franken, liess das BAG verlauten, nachdem es eine entsprechende Studie in Auftrag gegeben hatte. Mit Zahlen wollte das BAG beweisen, dass sich Prävention lohnt. Trotzdem schickte das Parlament das Präventionsgesetz schliesslich bachab. Das Kostenargument kann auch dazu verwendet werden, ungesundes Verhalten steuerlich zu sanktionieren. Bereits seit 1925 kennt die Schweiz eine Tabaksteuer, die der AHV zugutekommt. Die WHO bezeichnet, unter Berufung auf Studien, die Erhöhung der Tabaksteuer als wirksamste Methode der Tabakprävention, doch der Bundesrat nutzt dieses Instrument nur zögerlich und in kleinen Schritten. Die politische Forderung nach einer «Fettsteuer» blieb im Schweizer Parlament ohne Chance. Auch politische Vorstösse, die höhere Krankenkassenprämien verlangten für Leute, die mit ihrem ungesunden Lebenswandel Kosten verursachen, waren bisher erfolglos. Ebenso solche, die Wohlverhalten belohnen wollten, was auf dasselbe hinausläuft. Die Hürde des Parlaments schaffte einzig die Abschaffung der Kassenpflicht für Partygänger, die sich ins Koma gesoffen haben und zum Ausnüchtern im Notfall landen. Alle diese Entscheide fielen entgegen eindeutiger Empfehlungen der meisten Experten. Wo gesunder Menschenverstand und wo eher der Bauch den Ausschlag gab, bleibe dahingestellt.

\section{Trotzdem schickte das Parlament das}

Präventionsgesetz schliesslich bachab.

Seit es die Gesundheitsökonomie gibt, haben Zahlen in der Gesundheitspolitik Konjunktur. Ökonomen zählen qualitätsbereinigte Lebensjahre, berechnen die Kosten von Diabetes oder messen die Wirtschaftlichkeit von Screenings. Aber der Verdacht bleibt, dass all die Rechnereien vor allem Alibiübungen sind: Nachdem die Expertinnen sich geäussert haben, kommen andere Entscheidungsmechanismen zum Einsatz. Im besten Fall ist es eine Kombination aus Zahlen, Bauch und gesundem Menschenverstand. Und doch tun alle so, als politisierten sie ausschliesslich fakten- und evidenzbasiert. 